\title{
Innovative technology of flour confectionery products for therapeutic and preventive nutrition of patients with diabetes mellitus
}

\author{
Maria Zaikina ${ }^{1}$, Ksenia Chebotareva $^{1}$ and Anastasia Gurenko ${ }^{1,2}$ \\ ${ }^{1}$ Southwest State University, 305040, 50 Let Oktyabrya str., 94, Kursk, Russia, \\ ${ }^{2}$ School 2, 130001, Aktau city, Mangystau region, 3rd microdistrict, 2/1, Kazakhstan, \\ e-mail:zaikina.marija@yandex.ru
}

\begin{abstract}
Recently, much attention has been paid to the introduction of raw materials with a low glycemic index into the food industry, among which buckwheat, oat and barley flour occupy a special place. The use of raw materials with a low glycemic index in the formulation of flour confectionery products makes it possible to improve both the organoleptic and physicochemical properties of the product. They also allow to reduce the energy value of such products by reducing the amount of wheat flour, low-calorie margarine, melange and at the same time significantly increase the biological value of the food product. With the aim of adjusting the chemical composition, three recipes for cookies have been developed - wheat-oat, wheatbuckwheat and wheat-barley, with the replacement of water in the recipe with an infusion from the collection of herbs "Arfazetin-E", replacing part of the low-calorie margarine with linseed oil, with the addition of wheat flakes and flaxseed, as well as an aqueous solution of sorbitol and stevioside, apple pectin, iodized salt and flavocene (dihydroquercetin). The introduced components will improve the structural and mechanical properties of the dough, organoleptic and physicochemical indicators of the finished product, and bring the composition closer to the formula for balanced nutrition. The use of unconventional raw materials with a low glycemic index in the food industry makes it possible to enrich the chemical composition of biscuits with dietary fiber, vitamins, and mineral components. From the results of the analysis of the nutritional value, it follows that the finished product contains vitamins B1, B2, $\beta$-carotene and E, which can be used for therapeutic and prophylactic nutrition. The use of non-traditional raw materials of vegetable origin in the recipe for cookies leads to an increase in the biological value of the product and a decrease in its calorie content.
\end{abstract}

\section{Introduction}

Diabetes mellitus is one of the sources of the noninfectious pandemic in the XXI century. The number of patients with diagnoses of "prediabetes" and "diabetes mellitus" is steadily growing from year to year. Every ten seconds, there are two more diabetic patients in the world [1].

Diabetes mellitus develops in the cases when the body does not produce enough insulin by the pancreas. In absence of insulin, a lack of glucose in the blood leads to a feeling of hunger and patients develop polyphagia excessive food intake. Despite the excessive consumption of food, patients lose weight. This is due to the fact that the energy obtained from food, mainly in the form of carbohydrates, is not utilized by the body, leading to an increase in blood glucose [2].

The use of foods with a low glycemic index in the diet improves the degree of compensation for diabetes mellitus. One of the most important factors affecting the glycemic index is the content of dietary fiber in the product.

Dietary fiber slows down the flow of food into the intestines and the absorption of carbohydrates. As a result, the level of glucose in the blood rises much more slowly, dietary fiber leads to faster saturation and thereby prevents overeating and high cholesterol levels in the blood, which is very important for consumers with diabetes. Similar to polyphenols, dietary fiber does not have nutritional properties since it cannot be digested by the human organism, but it contributes to proper intestinal transit while retaining compounds and slowing glucose, lipid, sterol, and bile acid absorption $[3,4,5]$.

The dietary nutrition of patients with diabetes mellitus is one of the most important components of drug treatment success.

The use of diet therapy can significantly reduce the number of pharmaceuticals, and in some cases makes it possible to completely abandon them and significantly increase the effectiveness of treatment. Contemporary diet therapy includes requirements such as the use of 
carbohydrate-containing foods with a low glycemic index in the diet, an increase in the proportion of protein substances, a moderate intake of fat: restriction of saturated fat and an increase in the proportion of polyunsaturated fatty acids, increased intake of calcium [6].

The consumer market for diabetic food products, including flour confectionery products, is very limited, although the number of diseases of the population with diabetes is increasing. In this regard, it is relevant to increase the biological value of products, improve technology and expand the range of diabetic food products, taking into account modern requirements for diet therapy. Flour confectionery products made from wheat flour have a high glycemic index (100), which can be reduced by replacing wheat flour with ingredients with a lower glycemic index in the recipe [7].

\section{Materials and methods}

When developing diabetic cookies with improved quality indicators, non-traditional types of raw materials have been used.

Three types of cookies have been developed: wheatoat, wheat-buckwheat and wheat-oat. We used wheat flour of the 1st grade, varietal barley flour, buckwheat and oatmeal, Arfazetin-E herbal infusion, low-calorie margarine, flaxseed oil, skimmed milk powder, melange, wheat flakes of the germ and flaxseed, crushed to particles of size $0,1-2 \mathrm{~mm}$, sorbitol, stevioside, apple pectin, iodized salt and flavocene (dihydroquercetin).

As stated above, flour confectionery products made from wheat flour have a high glycemic index (100); it can be reduced by replacing part of the flour with wheat ingredients with a lower glycemic index in the recipe. These ingredients include flour from some cereals, in particular, oatmeal, buckwheat, barley flour.

Oat flour has a low starch content. The flour protein contains all the essential amino acids (unbalanced only by lysine and threonine). Oat flour contains an increased content of micro-and macronutrients, especially potassium, magnesium, and iron. The composition of oats includes beta-glucan-a soluble dietary fiber (soluble fiber). For decades, many scientific studies have established the health benefits of oats in lowering glycemic response, reducing blood cholesterol level, balancing gut microbiota, and regulating blood pressure [8].

Barley flour is rich in high-grade proteins containing a lot of lysine and tryptophan. Compared with wheat flour of the first grade, it contains more potassium (1.2 times), calcium (almost 2 times), magnesium (1.5 times).

Barley is naturally high in dietary fibre, especially $\beta$ glucan and phenolic compounds, which have the potential to lower cholesterol and blood glucose levels and helps gut microbial balance $[9,10]$. The composition of barley, which is especially valuable, also includes beta-glucan. Barley is traditionally used in Iraq for the treatment of diabetes.

Buckwheat is a rich source of starch, protein, and vitamins [11]. In terms of threonine content, buckwheat surpasses wheat and rye, in terms of valine, leucine and phenylalanine it can be equated to milk and beef, in terms of tryptophan content it is not inferior to animal products. Health benefits attributed to buckwheat include plasma cholesterol level reduction, neuroprotection, anticancer, anti-inflammatory, antidiabetic effects, and improvement of hypertension conditions [12].

Considering the above, oat flour (glycemic index $78 \%$ ), barley flour (glycemic index 90\%), buckwheat flour (glycemic index 78\%), as well as sources of dietary fiber - wheat germ flakes (flour) (glycemic index 53\%).

Wheat germ flakes are a by-product of the milling industry.

Stevioside and sorbitol were used as sugar substitutes. Enzymatic-glycosylated stevia extract contains several glucosides in the following proportions in \%: stevioside 9-11\%; rebaudioside A - 9-14\%; monoglucosyl stevioside and rebaudioside A - 23-28\%; diglucosyl stevioside and rebaudioside A - 22-26\%; triglucosyl steviosides and rebaudioside A - 10-14\%; other glucosyl steviosides and rebaudioside A-11-14\%; rebaudioside C, Dulcoside A and derivatives $7-11 \%$ [13].

The sugar-reducing ability of plant products is due to dietary fibers (pectin, cellulose, hemicellulose, etc.), which are not absorbed and prevent the absorption of digestible food carbohydrates and other active substances into the blood.

Instead of water in the recipe of diabetic cookies, it is proposed using an aqueous infusion of the herbs collection "Arfazetin-E". The composition of the collection includes blueberry shoots and bean fruit leaves$20 \%$; rhizome with eleutherococcus roots, rosehip fruits$15 \%$ each; St. John's wort grass, horsetail grass and chamomile flowers- $10 \%$ each.

The components of the Arfazetin-E herbal infusion contain vitamins of group B, PP, C, P-active substances, $\beta$-carotene, as well as mineral substances - $\mathrm{Na}, \mathrm{Mg}, \mathrm{Si}, \mathrm{P}$, $\mathrm{Ca}, \mathrm{Cr}, \mathrm{Fe}, \mathrm{Si}, \mathrm{Mn}, \mathrm{Zn}$, etc. Used as a hypoglycemic and tonic for the prevention and treatment of mild to moderate diabetes mellitus. There is information that with the constant use of the collection, the risk of damage to the eyes, kidneys, liver and cardiovascular system, characteristic of diabetes mellitus, decreases, the state of health significantly improves, and it also becomes possible to reduce the doses of antidiabetic drugs, and in case of mild diabetes, even refuse them [14].

It is also proposed to introduce flavocene (dihydroquercetin), an antioxidant and biologically active substance of natural origin, with P-vitamin activity, antioxidant, bacteriostatic, capillary-protective properties, into the bakery recipe.

Flavocene is introduced into a hot infusion from the herbs collection "Arfazetin-E" at a temperature of $85^{\circ} \mathrm{C}$ in an amount of $0.01 \%$ of the mass of the finished product. The mixture is thoroughly mixed until it is evenly distributed into the product. The dosage of flavocene is determined in terms of dihydroquercetin.

The freshly processed products were examined according to organoleptic and physico-chemical parameters by standard methods.

The nutritional value of biscuits for dietary purposes was characterized by the degree of the main nutrients 
balance, amino acid composition, and the content of vitamins and minerals. The theory of adequate nutrition does not only provide for the presence of complete proteins and fats in foods. It is necessary that all nutrients, including minerals and vitamins, enter the body at the same time and in optimal proportions.

The chemical composition of the developed cookies and the level of satisfaction of the need for individual nutrients at the rate of product consumption of $100 \mathrm{~g}$, as well as taking into account the results of determining the food components and the daily requirement of patients with diabetes mellitus in these substances, were determined by calculation using the Microsoft Excel application package.

Thus, the technology for the production of diabetic cookies was developed, the consumer properties of the finished product were analyzed and the nutritional value was assessed. The proposed product has an improved component composition. The main goal was to reduce the nutritional value of cookies by introducing ingredients with a lower glycemic index into the formulation.

\section{Equations and mathematics}

When developing recipes, much attention was paid to the ratio of flour in three types of cookies. For wheat-barley and wheat-oat cookies, the flour ratio was 70:30, and for wheat-buckwheat 60:40. The introduction of such proportions is explained by different values of the moisture-retaining ability of these flour types.

The content of wheat germ flakes to the total mass of flour in each of the types of cookies was provided in an amount of at least $10 \%$. Additionally, the developed cookies were enriched with pectin (at least 1\%). To increase the antioxidant properties and enrich it with $\mathrm{P}$ active substances - flavocene, $0.1 \%$ per $1000 \mathrm{~kg}$ of flour, i.e. $20.0 \%$ of the daily consumption rate, was introduced into the dough recipe.

The linseed oil included in the recipe was introduced in an amount of $4.5-5.5 \%$ of the flour weight due to the different values of the fat modules of the flour types used.

The amount of the prepared infusion "Arfazetin-E" was introduced taking into account the moisture-retaining ability of the flour. As for the introduction of sweeteners, they were taken in an amount from $13.5 \%$ to $14.6 \%$ in terms of dry matter.

The production of cookies is carried out according to traditional technology, but the use of non-traditional raw materials creates its own peculiarities.

The collection of herbs "Arfazetin-E", previously crushed and sifted from dust, is placed in an enamel container, poured with boiling water in a ratio of 1:50 (respectively, for 1 part of the collection to 50 parts of water) and infused in a water bath at a temperature of $90^{\circ}$ $\mathrm{C}$ for $15 \mathrm{~min}$, and then cooled. Raw materials are squeezed out and filtered. The volume of the resulting infusion is brought to the original with boiled water.

During the process of preparing the emulsion, the baking powder is prepared in the form of a solution, using an infusion of herbs instead of water in a ratio of 35 parts of baking powder per 100 parts of the infusion.
Sweeteners (sorbitol and stevioside), iodized salt are sieved and dissolved in Arfazetin-E herbal infusion, with a concentration of 70 to $80 \%$.

Wheat, oatmeal, barley and buckwheat flour, skimmed milk powder, cinnamon, vanillin, apple pectin, provided according to the recipe, are pre-sieved and weighed.

Apple pectin is poured with an infusion of herbs at a temperature of at least $80^{\circ} \mathrm{C}$ in a ratio of $1: 50$ and mixed until a homogeneous mixture is obtained, avoiding lumps. After that, the pectin is heated to a boil, stirring occasionally, preventing the remaining pectin lumps from burning, and cooled. When added to the prescription mixture, the pectin solution is pre-cooled.

The emulsion is prepared in a periodic and continuous way in an emulsifier. Softened margarine and melange are loaded into the kneading machine. Previously, the baking powder is dissolved in the infusion from the collection of herbs "Arfazetin-E". All liquid components and a solution of sugar substitutes (sorbitol, stevioside) are loaded into the emulsifier at a working speed at a temperature of $35^{\circ} \mathrm{C}$ and a concentration of $70-80 \%$, mixed for 5-10 minutes. Then add skimmed milk powder according to the recipe (for cookies using oat flour) and a chemical baking powder previously dissolved in an infusion of herbs "Arfazetin-E" (infusion temperature $17-20^{\circ} \mathrm{C}$ ).

Last of all, low-calorie margarine with a temperature of $40^{\circ} \mathrm{C}$ and linseed oil are added. Everything is thoroughly mixed until a homogeneous consistency is first 7-10 minutes in the emulsifier, and then-15-20 minutes in the kneading machine (with the periodic method).

The infusion of herbs "Arfazetin-E", used for dissolving chemical baking powder, sugar substitutes, pectin and iodized salt, is taken from the total amount of the infusion going to the batch. When using skimmed milk powder in the cookie recipe, it is introduced together with liquid components.

On the basis of experimental developments and organoleptic indicators of the cookies quality for patients with diabetes mellitus, the dosages of prescription components have been established, taking into account the optimal ratio of proteins, fats and digestible carbohydrates.

Thus, the consumption of raw materials per $100 \mathrm{~g}$ of the finished product of wheat-buckwheat cookies is: wheat flour-22.8\%, buckwheat flour $16.3 \%$, sorbitol$11.4 \%$, stevioside $0.09 \%$, infusion "Arfazetin-E" 21.2\%, wheat germ flakes- $4.1 \%$, flaxseed $-1.7 \%$, linseed oil $2.4 \%$, apple pectin- $0.08 \%$, flavocene- $0.008 \%$.

For the recipe of wheat - oat cookies, the consumption of raw materials per $100 \mathrm{~g}$ of the finished product is: wheat flour $-28.4 \%$, oat flour - $12.1 \%$, sorbitol $10.5 \%$, stevioside $0.09 \%$, infusion of "Arfazetin-E" 20.9\%, wheat germ flakes $-4.1 \%$, flaxseed and oil are the same as in the previous sample $(1.7 \%$ and $2.4 \%$, respectively), apple pectin $-0.08 \%$, flavocene $-0.008 \%$.

The consumption of raw materials per $100 \mathrm{~g}$ of the product in the recipe of wheat-barley cookies is: wheat flour-28.4\%, barley flour-12\%, sorbitol and stevioside $0.84 \%$, infusion "Arfazetin-E" $20.7 \%$, the consumption of wheat germ flakes and linseed oil and seed coincides with 
the recipe of wheat-oat and wheat-buckwheat cookies, apple pectin- $0.08 \%$, flavocene- $0.008 \%$.

Freshly produced products have been examined for organoleptic and physicochemical indicators using standard methods.

The organoleptic assessment of the biscuits quality was carried out according to a standard 30-point scale, developed on the basis of the requirements for the organoleptic characteristics of sugar biscuits. The scale was developed based on the requirements for the liver. The following indicators were determined: "taste", "smell", "color", "appearance at a break", "shape", "surface". A product that received at least one of the specified quality indicators a score below 2.6 points was considered poor quality.

The organoleptic evaluation results of the cookies were obtained on the basis of the tasting sheets of the commission members and presented in the form of a summary Table 1.

Table 1. Organoleptic evaluation of cookie samples based on sugar substitutes and hypoglycemic medicinal and technical raw materials (using a 5-point scale)

\begin{tabular}{|c|c|c|c|c|}
\hline \multirow{2}{*}{$\begin{array}{l}\text { Organoleptic } \\
\text { indicators, } \\
\text { points }\end{array}$} & \multicolumn{4}{|c|}{ Cookie name } \\
\hline & $\sum^{\bar{E}}$ & 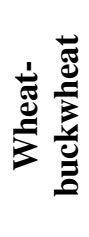 & 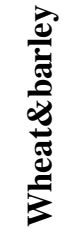 & 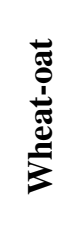 \\
\hline Flavor & 4.3 & 4.71 & 4.4 & 4.61 \\
\hline Scent & 4.0 & 4.7 & 4.3 & 4.2 \\
\hline Color & 4.1 & 4.6 & 4.3 & 4.4 \\
\hline $\begin{array}{l}\text { View at the } \\
\text { break }\end{array}$ & 4.1 & 4.5 & 4.3 & 4.3 \\
\hline Shape & 4.1 & 4.6 & 4.2 & 4.5 \\
\hline Surface & 4.0 & 4.4 & 4.1 & 4.3 \\
\hline Points total & 24.6 & 27.5 & 25.6 & 26.3 \\
\hline
\end{tabular}

During the tasting, an organoleptic quality assessment in points was carried out for each quality indicator.

The freshly processed products received a high score according to organoleptic indicators. The highest amount of points were received - cookies "Useful" with oat flour (26.3 points) and cookies "Useful" with buckwheat flour (27.5 points).

The study of physical and chemical quality indicators of wheat (control) and freshly processed diet cookies is presented in Table 2.

The mass fraction of moisture of new types cookies is higher compared to the control by $18.0-20.0 \%$, which is explained by the introduction of raw materials with increased water absorption capacity. The mass fraction of sorbitol in terms of dry matter is different, which is explained by the amount of sorbitol introduced into the formulations. In the control cookie sample, the sorbitol is higher on average by $25.8 \%$ compared to the developed cookie samples.

Table 2. Physical and chemical quality indicators of wheat and freshly processed developed dietary cookies

\begin{tabular}{|c|c|c|c|c|}
\hline \multirow[b]{2}{*}{$\begin{array}{l}\text { Name of the } \\
\text { indicator }\end{array}$} & \multicolumn{4}{|c|}{ The value of the indicator } \\
\hline & 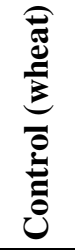 & 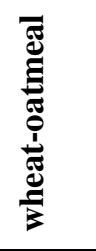 & 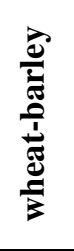 & ש \\
\hline $\begin{array}{l}\text { Mass fraction of } \\
\text { moisture. } \%\end{array}$ & 9.0 & 10.6 & 10.7 & 10.8 \\
\hline $\begin{array}{l}\text { Mass fraction of } \\
\text { sorbitol in terms } \\
\text { of dry matter. \% }\end{array}$ & 19.0 & 13.5 & 14.6 & 14.6 \\
\hline $\begin{array}{l}\text { Mass fraction of } \\
\text { stevioside in terms } \\
\text { of dry matter. \% }\end{array}$ & - & 1.2 & 1.2 & 1.2 \\
\hline $\begin{array}{l}\text { Mass fraction of } \\
\text { fat in terms of dry } \\
\text { matter. \% }\end{array}$ & 12.0 & 10.9 & 10.8 & 10.8 \\
\hline Alkalinity. deg. & 2.0 & 1.6 & 1.7 & 1.8 \\
\hline $\begin{array}{l}\text { Mass fraction of } \\
\text { ash, insoluble in a } \\
\text { solution with a } \\
\text { mass fraction of } \\
\text { hydrochloric acid } \\
10 \% . \%\end{array}$ & 0.1 & 0.1 & 0.1 & 0.1 \\
\hline $\begin{array}{l}\text { Mass fraction of } \\
\text { total sugar in } \\
\text { terms of dry } \\
\text { matter. \% }\end{array}$ & 2.3 & 1.9 & 1.7 & 1.8 \\
\hline
\end{tabular}

The total alkalinity in new types of cookies is 1.6-1.8 degrees, and in wheat cookies (control) - 2.0. The alkaline reaction of cookies is due to the presence of soda or ammonia formed during the decomposition of chemical baking powder.

The alkalinity should not be very high in the finished product, since the increased content of soda and ammonia worsens the taste of the products. The studied samples of dietary cookies in terms of alkalinity met the requirements of the standard.

New prescription components contribute to an increase in the amount of protein, dietary fiber, and a decrease in digestible carbohydrates in $100 \mathrm{~g}$ of products.

In order to select such ingredients, a functional analysis of raw materials was carried out, which showed the possibility of using flour from various cereals (oat, buckwheat and barley), wheat germ flakes, pectin substances, etc. to create diabetic cookies.

The ratio of proteins, fats and carbohydrates in this method of producing diabetic cookies is optimal and is 1 : 1.4: 3.4 .

Nutritional value of "Useful" biscuits for diabetic purposes is characterized by a limited content of carbohydrates, a high content of proteins and polyunsaturated fatty acids.

Based on the results of determining the chemical composition of cookies using medicinal and technical raw materials for diabetic purposes, their nutritional value was calculated, as well as the level of satisfaction of the daily requirement for the necessary food components when using 100 grams of cookies per day. 
Compared to the chemical composition of the existing type of dietary biscuits, the new types have a significantly higher composition of minerals and the presence of vitamins and fiber. This is due to the introduction of raw materials richer in these substances into the recipe (various types of flour from cereals, wheat germ flakes, flax seeds and an infusion from medicinal and technical raw materials "Arfazetin - E").

According to the research results, the new types of cookies contain in $100 \mathrm{~g}$ from $8.5 \%$ to $9.5 \%$ protein, from 10.8 to $10.9 \%$ fat, from 37.4 to $48.4 \%$ digestible carbohydrates and $4.0 \%$ fiber.

The cookies contain vitamins B1, B2, PP, A, betacarotene and $\mathrm{E}$ passing from the main and additional raw materials. Nutrients are in a state that promotes their easy assimilation. The protein substances of the cookies are in the optimal stage of denaturation, the starch is partially gelatinized and partially converted to a soluble state, the fat is emulsified.

The chemical composition of the new types of cookies determines their caloric content from 284.0 to $321.6 \mathrm{kcal}$ per $100 \mathrm{~g}$. The average digestibility of the dry matter of cookies is 90.0-95.5\%. Thus, when consuming an average of $100 \mathrm{~g}$ of cookies, a diabetic patient receives an average of $302.8 \mathrm{kcal}$. This is approximately $12.0 \%$ of a person's daily need for food energy substances.

One of the most important is the problem of the biological value of flour confectionery products. The protein substances of cookies contain essential amino acids. In terms of the amount of proteins of the new type of cookies, they cover up to $10.0 \%$ of the need for this food substance. The disadvantage of cookie proteins, as well as proteins of wheat and flour from cereals, is the relatively low content of the amino acid lysine in them. The essential amino acid lysine plays a role in the body's defense reactions.

The mineral composition of wheat-oat cookies based on medicinal and technical raw materials is theoretically characterized by a high content of potassium $-27.5 \%$, iron $-28.7 \%$, phosphorus $-40.25 \%$, magnesium $-21.7 \%$ of the daily consumption rate and a small amount of zinc, manganese, chromium compared to other types.

The developed cookies of three names contain a significant amount of vitamins B1, B2, beta-carotene and E. Minerals $100 \mathrm{~g}$ of cookies based on medicinal and technical raw materials for diabetic purposes cover the human need as follows: in calcium - from 6.1 to $9.1 \%$, in phosphorus - from 34.6 to $40.3 \%$, in magnesium - from 16.4 to $21.7 \%$, in iron - from 21.7 to $30.1 \%$ and in potassium - from 21.4 to $27.5 \%$.

One of the most important factors of the cookies digestibility based on medicinal and technical raw materials was looseness, as well as the excellent taste, aroma and look of the product. The presence of numerous macro-and micropores creates a very large total contact surface of the cookie with digestive juices.

Thus, due to the introduction of sorbitol and stevioside, the addition of wheat germ flakes, edible flax seeds and infusion from medicinal and technical raw materials to new types of cookies, its calorie content decreased and amounted to $321.6 \mathrm{kcal}$ for wheat and barley, 329 for wheat and oat., $7 \mathrm{kcal}$, for wheatbuckwheat - 284.0 kcal.

The analysis of the percentage of satisfaction of the daily requirement for the content of protein substances, fiber, vitamins, macro- and microelements showed that the developed types of cookies exceed the values of the basic cookie.

The proposed technology for the production of flour confectionery for diabetic purposes allows to slow down the absorption of glucose by the intestinal mucosa.

\section{Conclusion}

The developed flour confectionery product is promising from the point of view of dietary nutrition for patients with diabetes mellitus. Its consumption helps to reduce the level of glucose in the blood and increase the body's defences.

The combination of concentration, temperature, dosage of a solution from sugar substitutes, as well as the introduction of wheat flour together with other types of flour (barley, buckwheat or oat), with wheat germ flakes and with other ingredients makes it possible to improve the structural and mechanical properties of the product, organoleptic characteristics, bring the composition closer to a balanced nutrition formula.

The use of wheat flakes of the germ, flour from cereals (oat, barley and buckwheat), flaxseed oil, stevioside and pectin can reduce the energy value of diabetic cookies by reducing the amount of wheat flour, low-calorie margarine, melange and at the same time significantly increase the biological value of the food product.

The additional amount of water in the dough bound by the fibers and pectin substances prevent the biscuits from drying out. At the same time, the activity of water decreases, the texture of the product is strengthened, the yield of finished products increases, the shelf life of cookies increases, microbiological spoilage slows down, and organoleptic indicators improve.

\section{References}

1. A. B. Evseev, Bulletin of Science and Practice 5 (10) 77 (2019)

2. A. A. Demin, Clinical medicine 54 (2003)

3. E. Lecumberri, R. Mateos, M. Izquierdo-Pulido, P. Rupérez L. Goya Food Chem 104948 (2007)

4. J. Nsor-Atindana, F. Zhong, K. J. Food Funct 31044 (2012)

5. H. H. Sharafetdinov, V. A. Meshcheryakova, Nutrition issues 330 (1998)

6. I. I. Mersiyanova, Yu. A. Knyazev, M. V. Burdenko, T. V. Sebko, Yu. V. Evgrafov, Problems of endocrinology 43 (1995)

7. M. A. Zaikina, E. D. Polyakova, Bread products 2, 44 (2011)

8. K. Zhang, R. Dong, X. Hu, Ch. Ren, Y. Li, Foods 10 (6) 1304 (2021)

9. M. Martínez, M.-J.Motilva, M.-C. López de las 
Hazas, M.-P. Romero, K. Vaculova, I. A. Ludwig, Food Chem. 24561 (2018)

10. H. R. Komeili, Z. Sheikholeslami, Adv. Biol. 239 (2014)

11. P. Van Hung, N. Morita, Food Chem., 109, 325 (2008)

12. J. A. Giménez-Bastida, H. Zieliński, Food Chem., 63, 7896 (2015)

13. R. Lemus-Mondaca, A. Vega-Galvez, L. Zura-Bravo, K. Ah-Hen, Food Chem. 1321121 (2012)

14. 14 V. D. Korotkova , Problemy jendokrinologii 34 (4) 25 (1989) 